\title{
An Improved Prediction of Pre-Combustion Processes, Using the Discrete Multicomponent Model
}

\author{
Islam Kabil ${ }^{1} \oplus$, Mansour Al Qubeissi ${ }^{2, *}{ }^{\circledR}$, Jihad Badra ${ }^{3}$, Walid Abdelghaffar ${ }^{1}$, Yehia Eldrainy ${ }^{1,4}$, \\ Sergei S. Sazhin ${ }^{5}$, Hong G. Im ${ }^{6}$ and Ahmed Elwardany ${ }^{1,7, *}$
}

1 Mechanical Engineering Department, Faculty of Engineering, Alexandria University, Alexandria 21544, Egypt; Islam.Kabil@alexu.edu.eg (I.K.); wabdelghaffar@hotmail.com (W.A.); YEldrainy@alexu.edu.eg (Y.E.)

2 Faculty of Engineering, Environment and Computing, Coventry University, Coventry CV1 2JH, UK

3 Fuel Technology Division, R\&DC, Saudi Aramco, Dhahran 34465, Saudi Arabia; Jihad.Badra@aramco.com

4 Mechanical Engineering Department, Arab Academy for Science, Technology and Maritime Transport, Alexandria 1029, Egypt

5 Sir Harry Ricardo Laboratories, School of Computing, Engineering and Mathematics, University of Brighton, Brighton BN2 4GJ, UK; S.Sazhin@brighton.ac.uk

6 Clean Combustion Research Center, King Abdullah University of Science and Technology, Thuwal 23955, Saudi Arabia; Hong.Im@kaust.edu.sa

7 Fuels and Combustion Engines Laboratory, Energy Resources Engineering Department, Egypt-Japan University of Science and Technology, New Borg El-Arab 21934, Egypt

* Correspondence: ac1028@coventry.ac.uk (M.A.Q.); Ahmed.Elwardany@ejust.edu.eg (A.E.); Tel.: +44-247-7658060 (M.A.Q.)

check for updates

Citation: Kabil, I.; Al Qubeissi, M.; Badra, J.; Abdelghaffar, W.; Eldrainy, Y.; Sazhin, S.S.; Im, H.G.; Elwardany, A. An Improved Prediction of Pre-Combustion Processes, Using the Discrete Multicomponent Model. Sustainability 2021, 13, 2937. https:// doi.org/10.3390/su13052937

Academic Editor:

Laurencas Raslavičius

Received: 19 December 2020

Accepted: 1 March 2021

Published: 8 March 2021

Publisher's Note: MDPI stays neutral with regard to jurisdictional claims in published maps and institutional affiliations.

Copyright: (c) 2021 by the authors. Licensee MDPI, Basel, Switzerland. This article is an open access article distributed under the terms and conditions of the Creative Commons Attribution (CC BY) license (https:// creativecommons.org/licenses/by/ $4.0 /)$.

\begin{abstract}
An improved heating and evaporation model of fuel droplets is implemented into the commercial Computational Fluid Dynamics (CFD) software CONVERGE for the simulation of sprays. The analytical solutions to the heat conduction and species diffusion equations in the liquid phase for each time step are coded via user-defined functions (UDF) into the software. The customized version of CONVERGE is validated against measurements for a single droplet of n-heptane and n-decane mixture. It is shown that the new heating and evaporation model better agrees with the experimental data than those predicted by the built-in heating and evaporation model, which does not consider the effects of temperature gradient and assumes infinitely fast species diffusion inside droplets. The simulation of a hollow-cone spray of primary reference fuel (PRF65) is performed and validated against experimental data taken from the literature. Finally, the newly implemented model is tested by running full-cycle engine simulations, representing partially premixed compression ignition (PPCI) using PRF65 as the fuel. These simulations are successfully performed for two start of injection timings, 20 and 25 crank angle (CA) before top-dead-centre (BTDC). The results show good agreement with experimental data where the effect of heating and evaporation of droplets on combustion phasing is investigated. The results highlight the importance of the accurate modelling of physical processes during droplet heating and evaporation for the prediction of the PPCI engine performance.
\end{abstract}

Keywords: combustion; computational fluid dynamics; droplet evaporation; engine simulation; spray

\section{Introduction}

In the pursuit of higher engine thermal efficiency and lower emissions, partially premixed compression ignition (PPCI) draws considerable attention [1,2]. This is mainly ascribed to the low-temperature combustion following this process. In such engines, manipulation of the degree of stratification of injected fuel into the engine cylinder by late injection at the end of the compression stroke controls the start of combustion.

Accurate simulation of the performance of PPCI engines mandates the proper description of the physical processes and properties. Spray dynamics dictate how the combustion process is going to develop during engine cycles [3]. These include a number of physical 
processes which range from jet/droplet heating and evaporation to the breakup, collision, and coalescence of droplets. Amsden et al. [4] have proposed a computationally efficient fuel droplet heating and evaporation model, which is implemented into CONVERGE as a zero-dimensional approach. This model, however, ignores the important effect of temperature gradients in droplets, which leads to an overprediction of droplet evaporation times [3]. This drawback in the latter model has stimulated the development of a more advanced model that takes into account the effects of temperature gradient, species diffusion, and recirculation inside a droplet [5,6]. The discrete multicomponent (DMC) model (see [7-9] for details) was a response to those drawbacks. A distinctive feature of this model is that it considers the effects of temperature gradient, species diffusion, and recirculation inside droplets using the effective thermal conductivity (ETC) and effective diffusivity (ED) models [10-13].

In three-dimensional engine simulations, an earlier effort to implement the ETC model into KIVA CFD code was made by Abdelghaffar et al. [14]. They investigated the effects of heating and evaporation (using the DMC model) on the predicted amounts of fuel vapour and in-cylinder pressure in a diesel engine. This implementation was important for single component fuels but lacked the inclusion of the effects of liquid species diffusion in the case of multicomponent fuels. To our knowledge, there have not been any modelling studies to describe the characteristics of multicomponent droplets into CFD codes for a full-cycle simulation. In recent studies [15,16], the DMC model was used for the analysis of single droplet and spray evaporation, with the implementation of the ETC/ED models into ANSYS Fluent. The ETC/ED models form an important part of the DMC model, in which each component is accounted for without approximation. These studies motivated the work on this paper to perform a similar analysis for a wider range of fuels and for a full combustion cycle.

The results of the implementation of the DMC model into CONVERGE are reported in this paper. The customised version of this software, with the new ETC/ED models implemented via the user-defined function (UDF), is applied to the analysis of droplet heating and evaporation and the dynamics of hollow-cone sprays. The new software has been successfully used for performing engine simulations, with an emphasis on the accurate analysis of fuel sprays under PPCI engine conditions.

\section{The Models}

The ETC/ED models used in our analysis are described in [10,17]. The transient heat and species diffusion equations are solved analytically for a spherically symmetric droplet:

$$
\begin{gathered}
\frac{\partial T}{\partial t}=\alpha_{l}\left(\frac{\partial^{2} T}{\partial r^{2}}+\frac{2}{r} \frac{\partial T}{\partial r}\right), \\
\frac{\partial Y_{l i}}{\partial t}=D_{l}\left(\frac{\partial^{2} Y_{l i}}{\partial r^{2}}+\frac{2}{r} \frac{\partial Y_{l i}}{\partial r}\right),
\end{gathered}
$$

where $T=T(r, t)$ is temperature; $\alpha_{l}=\frac{k_{l}}{c_{l} \rho_{l}}$ is the liquid thermal diffusivity; $\rho_{l}, k_{l}$, and $c_{l}$ are the liquid density, liquid thermal conductivity, and specific heat capacity, respectively; $r$ is the distance from the droplet centre; $t$ is time; $Y_{l i}=Y_{l i}(r, t)$ is the mass fraction of species $i$; and $D_{l}$ is the liquid species diffusivity calculated using the Wilke-Chang approximation [5]. The thermal and mass diffusivities were replaced by the effective thermal/mass diffusivity to consider the recirculation inside the liquid droplet [18]. The droplet mass evaporation rate, $\dot{m}_{d}$, is calculated as [18]:

$$
\dot{m}_{d}=-2 \pi R_{d} D_{v} \rho_{g} B_{M} \mathrm{Sh}_{i s o}
$$

where $\rho_{g}$ is the density of the mixture of vapour and air, assumed to be independent of the distance from the droplet surface; $B_{M}$ is the Spalding mass transfer number; and $\mathrm{Sh}_{\text {iso }}$ is the isolated droplet's Sherwood number, estimated following Abramzon and 
Sirignano [19]; and $D_{v}$ is the vapour binary diffusion coefficient calculated using the Wilke-Lee formula $[5,20]$.

\section{Results}

The model described in Section 2 has been implemented into CONVERGE via the user-defined function (UDF). The customised version of this software has been tested by comparing its predictions with the experiments performed by Daif et al. [21] using multicomponent fuel droplets. The results of the simulation of a hollow-cone spray of PRF65 fuel (65\% iso-octane/35\% n-heptane) will be presented, using the conventional version of CONVERGE based on the Amsden et al. model [4] and the customised version of this software. The full-cycle simulation of a PPCI engine is conducted, and the late injection timings are presented, using the customised version of the software with the new heating and evaporation model implemented into it.

\subsection{Single Droplet}

As a first step, the customised version of CONVERGE was used to reproduce the conditions of the experiment described by Daif et al. [21]. In this experiment, the initial droplet radius was $743 \mu \mathrm{m}$; the initial mass fractions of $\mathrm{n}$-heptane and $\mathrm{n}$-decane were $21.3 \%$ and $78.7 \%$, respectively; droplet relative velocity was $3.1 \mathrm{~m} / \mathrm{s}$; and its initial temperature was $294 \mathrm{~K}$, with ambient pressure and temperature equal to $0.101 \mathrm{MPa}$ and $348 \mathrm{~K}$, respectively.

The results predicted by CONVERGE with the new model, implemented via UDF, for the conditions of this experiment were compared with experimental data and the predictions of the model described in [4], which was implemented in the conventional version of CONVERGE. The results of this comparison are shown in Figure 1. In [4], it is assumed that the temperature and species distribution inside droplets are homogeneous, although they can change with time. As can be seen from Figure 1, the predictions made by CONVERGE with the new heating and evaporation model are very close to the experimental data. On the other hand, the predictions of this software with the conventional evaporation model show lower evaporation rates yielding larger droplets. This clearly demonstrates an improvement in CONVERGE prediction when the effects that were previously ignored are taken into account.

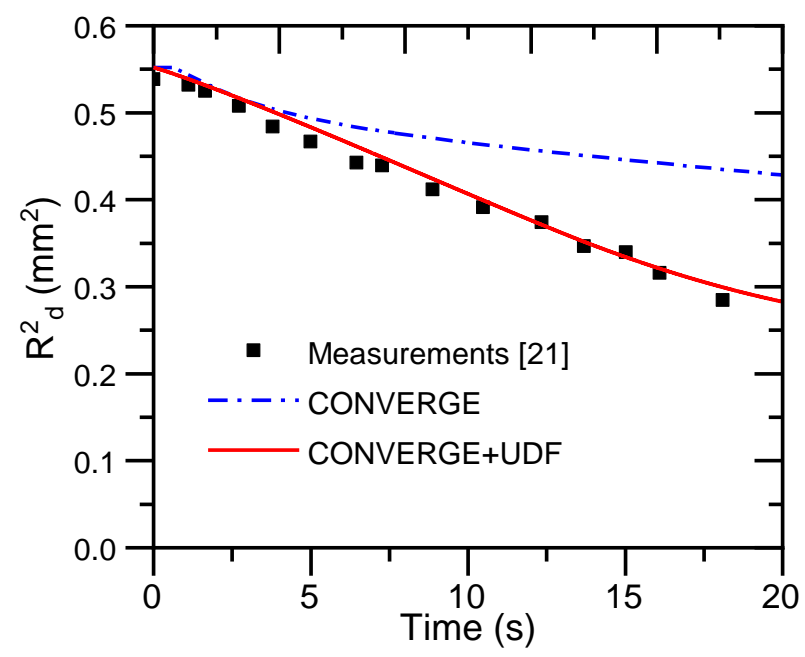

Figure 1. Predicted and measured squared radii of the fuel droplets versus time.

\subsection{Spray Simulation}

The customized version of CONVERGE was used to analyse a PRF65 hollow-cone spray. Its predictions were compared with the experimental data presented by Wang et al. [22]. A Lagrangian discrete parcel method was used, in which droplets of similar properties are grouped into parcels [23]. These parcels are then injected into the computational domain. 
For turbulence modelling, the Reynolds averaged Navier-Stokes (RANS)-based renormalization group (RNG) k- $\varepsilon$ model was used. The O'Rourke turbulent dispersion model, which accounts for fluctuating velocities, was used to model the effect of turbulent flow on the spray droplets. To describe the spray formation process, the modified Kelvin-Helmholtz and Rayleigh-Taylor (KH-RT) droplet breakup models were used, taking into account the contribution of the breakup length of the liquid jet $L_{b}$; droplets were formed and allowed to breakup when the jet reached $L_{b}$. Moreover, the dynamic drag model was used along with the no-time-counter (NTC) collision method, taking into account the post-collision regimes for better accuracy [24]. Injection velocities and droplet diameters are commonly calculated based on the nozzle diameter and mass flow rate [25]. This is the case for a solid-cone spray. However, an outwardly opening hollow-cone injector requires a more careful description of the process. The shape and area of the nozzle exit depend on the needle lift, which influences the injection velocities and droplet diameters (see Sim et al. [25] for the details). For the heating and evaporation of the droplet in spray, two models were used: that of Amsden et al. [4] (using the standard CONVERGE CFD tool) and the new model, which was implemented into CONVERGE via the UDF.

A property that is commonly targeted for spray behaviour is spray penetration length. PRF65 under 100 bar of pressure was injected into a chamber with an ambient pressure and temperature of 1 bar and $298 \mathrm{~K}$, respectively [22]. This spray was modelled assuming that it was injected into still air in a cylindrically shaped constant volume chamber with a height of $106.5 \mathrm{~mm}$ and a diameter of $150 \mathrm{~mm}$. For computational efficiency, a $4 \mathrm{~mm}$ base mesh size was used with an adaptive mesh refinement (AMR) to maintain the minimal cubic cell size of $0.125 \mathrm{~mm}$. Fixed AMR embedding was maintained at the nozzle exit, while dynamic AMR was triggered by flow fields based on temperature and velocity gradients. The injection actuation duration was $0.3 \mathrm{~ms}$, and the start of the injection was $0.012 \mathrm{~ms}$ after the end of this actuation. The whole injection took $0.36 \mathrm{~ms}$, which includes an opening period of $0.02 \mathrm{~ms}$ and a closing period of $0.06 \mathrm{~ms}$ (these were observed experimentally $[25,26]$ ). The total injected mass was $10 \mathrm{mg}$. The ambient temperature and pressure were $298 \mathrm{~K}$ and 1 bar, respectively.

The breakup parameters in both the conventional and new versions of CONVERGE were adjusted to reach a good agreement between our predicted spray penetration and the experimental data of [22], as shown in Figure 2. These versions of CONVERGE used the same parameters, except for the evaporation models. A slight difference in penetration length was observed. The new version of CONVERGE predicted slightly shorter penetration. This was demonstrated in [12] where different fuels were tested for hollow-cone spray setup using the two evaporation models. In contrast, a larger difference is revealed in the vapour masses predicted by two versions of CONVERGE, as shown in Figure 3. As expected from the single droplet simulations performed in the previous section, the total masses of PRF65 vapour predicted by both versions of CONVERGE turned out to be significantly different. The version with the new model predicts higher evaporation rates due to the fact it predicts higher surface temperatures for the fuel droplets. This highlights the influence that the choice of droplet heating/evaporation model has on simulations of fuel sprays. An accurate prediction of the fuel vapour mass flow rate would allow the users to have a clearer idea of the start of combustion in mixing-controlled engines, which operate at relatively lower temperatures, as in the case of PPCI engines. 


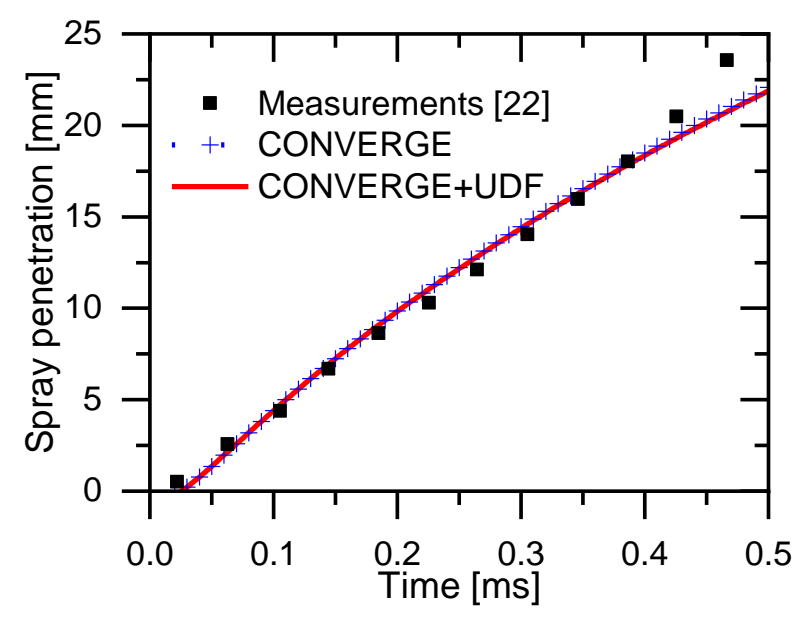

Figure 2. Measured spray axial penetration length and the values predicted by the conventional and customised versions of CONVERGE for PRF65 (primary reference fuel).

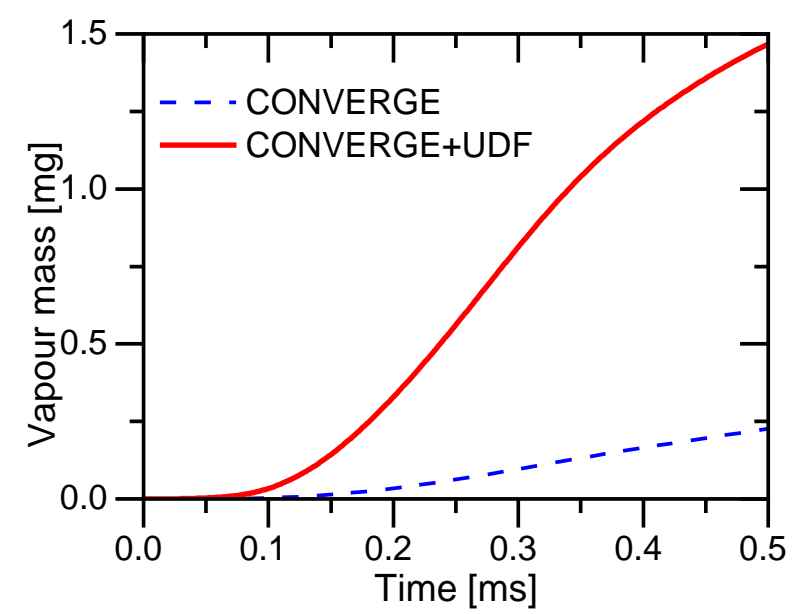

Figure 3. Comparison of the total vapour masses versus time for PRF65 calculated using the two versions of CONVERGE.

\subsection{Engine Simulation}

We investigated the effect of the accurate modelling of the heating and evaporation of fuel droplets on the values of chamber pressure as predicted by CONVERGE. The simulation results were compared with the results of experiments (inferred from [3]) using a PPCI engine running on PRF65. Those experiments were conducted on a single cylinder compression ignition research engine with a compression ratio of $17: 1$, with specifications as shown in Table 1. Injection was performed as a single pulse of fuel with an injection pressure of 300 bar from a seven-hole Bosch diesel injector with a 0.18 nozzle diameter and a BTDC (before top-dead-centre) $142^{\circ}$ spray angle. To achieve PPCI, two injection timings were tested: $20^{\circ}$ and $25^{\circ} \mathrm{CA}$ (crank angle) BTDC. The masses of the injected fuels were $9.6 \mathrm{mg}$ and $10.3 \mathrm{mg}$, respectively, with an initial fuel temperature of $360 \mathrm{~K}$. Injection durations were 5.04 CA and 5.41 CA, respectively. Changing the SOI (start of injection) from 25 to 20 BTDC was used to evaluate the effect of delayed injection on partially premixed combustion. At early injection timings, the air-fuel mixture is considered mostly homogeneous and combustion in this case is kinetically controlled. For late injections with low ambient temperatures, however, heating and evaporation processes in fuel sprays play a vital role in controlling the start of combustion. 
Table 1. Engine specifications used in our model.

\begin{tabular}{cc}
\hline Description & Specification \\
\hline Bore & $85 \mathrm{~mm}$ \\
Stroke & $90 \mathrm{~mm}$ \\
Connecting Rod Length & $138 \mathrm{~mm}$ \\
Compression ratio & $17: 1$ \\
Intake pressure & $100 \mathrm{KPa}$ \\
Intake temperature & $298 \mathrm{~K}$ \\
Engine displacement & $0.51 \mathrm{~L}$ \\
Bowl depth & $10 \mathrm{~mm}$ \\
Number of valves & 2 intake, 1 exhaust \\
Intake valve open (IVO) & $30 \mathrm{CA}$ BTDC \\
Intake valve close (IVC) & $45 \mathrm{CA} \mathrm{ATDC}$ \\
Exhaust valve open (EVO) & $50 \mathrm{CA} \mathrm{BBDC}$ \\
Exhaust valve close (EVC) & $25 \mathrm{CA}$ ABDC \\
\hline
\end{tabular}

The geometry of the computational domain was that of a real engine with the base grid chosen as $4 \mathrm{~mm}$ with fixed AMR embedding at the nozzle exit and dynamic AMR embedding in the fluid flow area, controlled by the velocity and temperature gradients, leading to a minimum cell size of $0.125 \mathrm{~mm}$ (see Figure 4). This is the same setup as in previous studies of the same engine and injector [3,27].

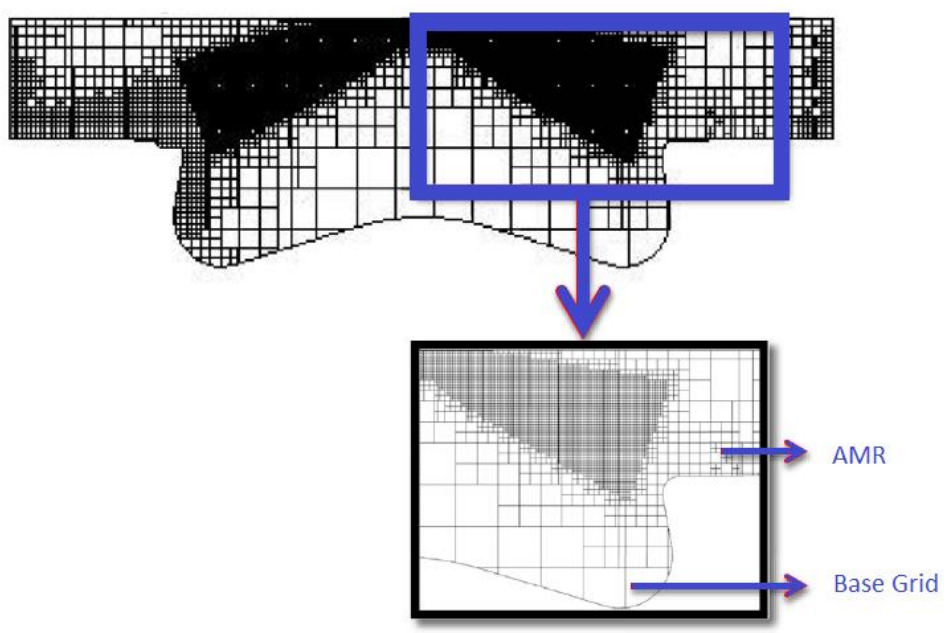

Figure 4. Mesh used for the single cylinder engine during spray event showing AMR (adaptive mesh refinement) refining the grid.

The RANS-based renormalization group (RNG) $k-\varepsilon$ model was used for turbulence modelling. For spray modelling, the modified KH-RT breakup model and NTC collision model were used. For heating and evaporation, the version of CONVERGE with the Amsden et al. model [4] and the new model were tested. The multizone detailed chemistry combustion sub-model of SAGE was used [28], with a reduced PRF chemical kinetic mechanism composed of 56 species and 168 reactions developed by Liu et al. [29], representing gas-phase combustion kinetics.

The equivalence ratio and temperature contours at various crank angle locations in the vicinity of the piston are shown in Figures 5 and 6 . Figure 5 shows that ignition starts for the case of SOI 20 right at the piston bowl surface. This is attributed to the high thermal conductivity of the hot piston surface and the swirling of air inside its bowl. As such, a high concentration of the fuel vapour (high equivalence ratio) is expected in this region (point A). Combustion starts at point A and spreads to the regions near the piston bowl surface where fuel vapour is abundant within flammability range.

In Figure 6, the contours of the temperature inside the engine cylinder are shown for the case of SOI 25. It is shown that ignition starts at a region near the piston bowl 
surface (point B). Ignition is predicted to start earlier in the case of SOI 25 than SOI 20. This is attributed to the earlier injection, which allows fuel vapour to diffuse into the air trapped inside the cylinder to form a mixture ready to react once heated to its combustion temperature. Before performing combustion simulations, matching with the motoring curve of the unfired engine at $1250 \mathrm{rpm}$ was achieved by adjusting the compression ratio of the engine to 15.7:1. This adjustment was made to consider the contribution of residual exhaust gases and blow-by. This allowed us to achieve an almost perfect agreement of the model predictions and experimental measurements, as shown in Figure 7.

Temperature of piston bowl

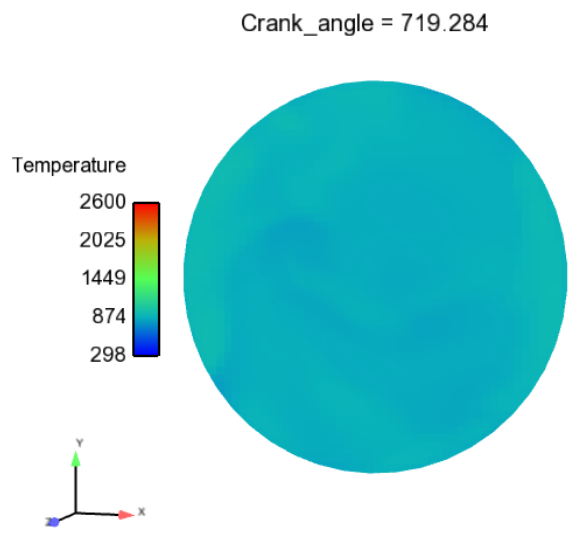

Crank angle $=720.281$

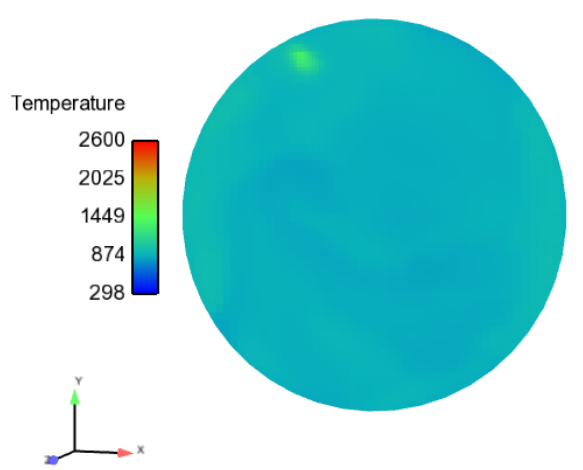

Crank_angle $=725.272$

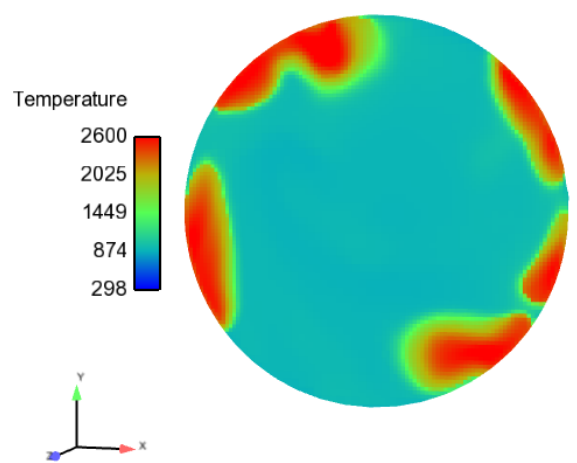

Equivalence ratio
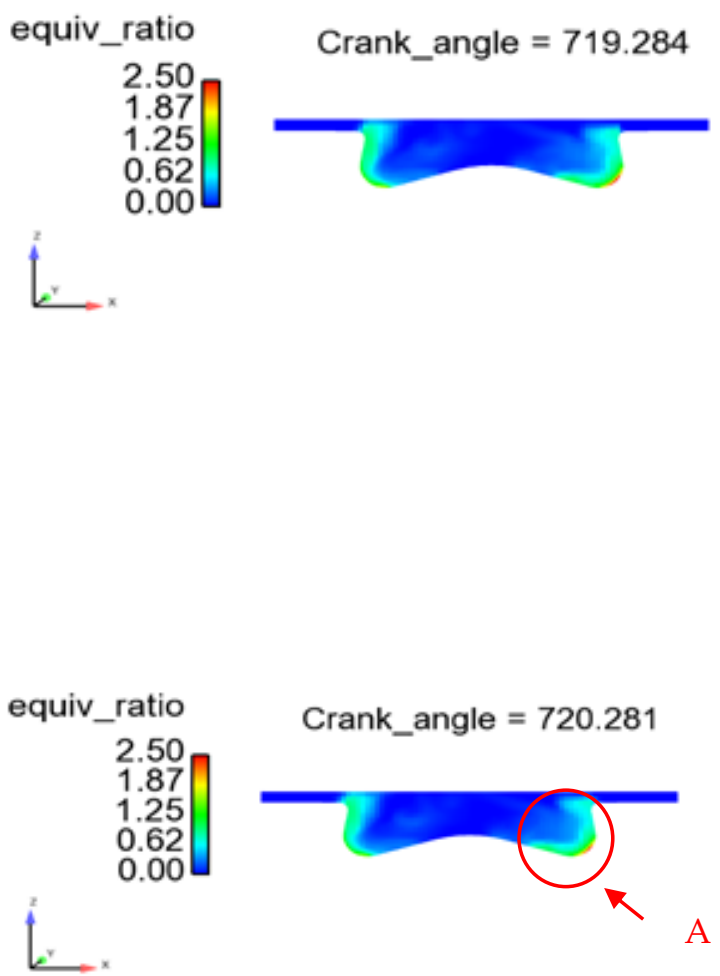

Crank_angle $=720.281$

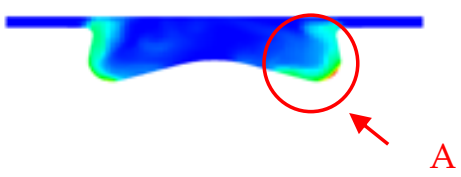

A

Figure 5. Cross-sections of the engine cylinder showing the temperature and equivalence ratio for SOI (start of injection) 20; the customised version of CONVERGE was used. 
Temperature

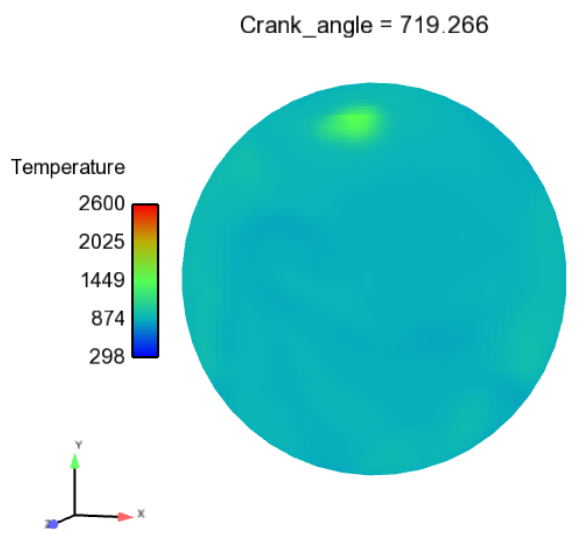

Crank_angle $=720.29$

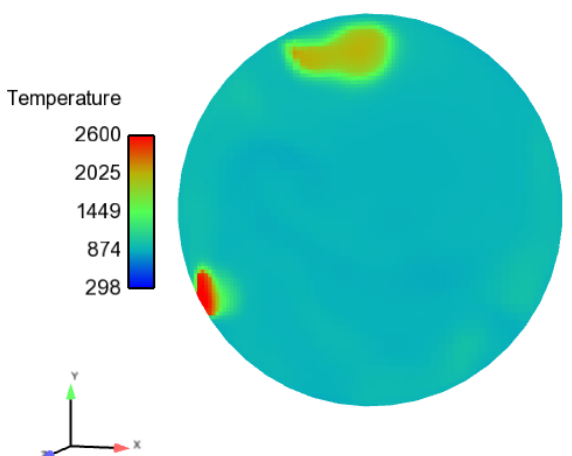

Crank_angle $=725.25$

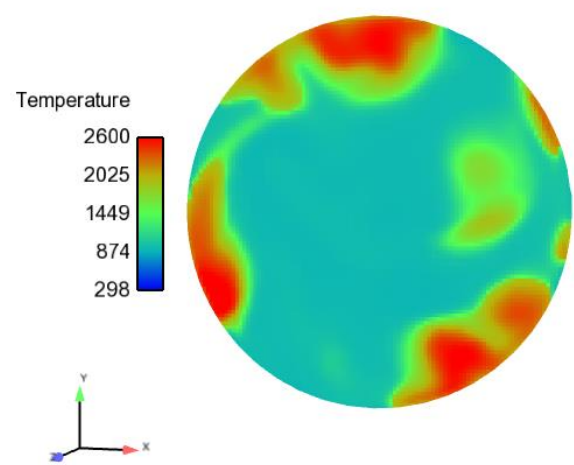

Equivalence ratio
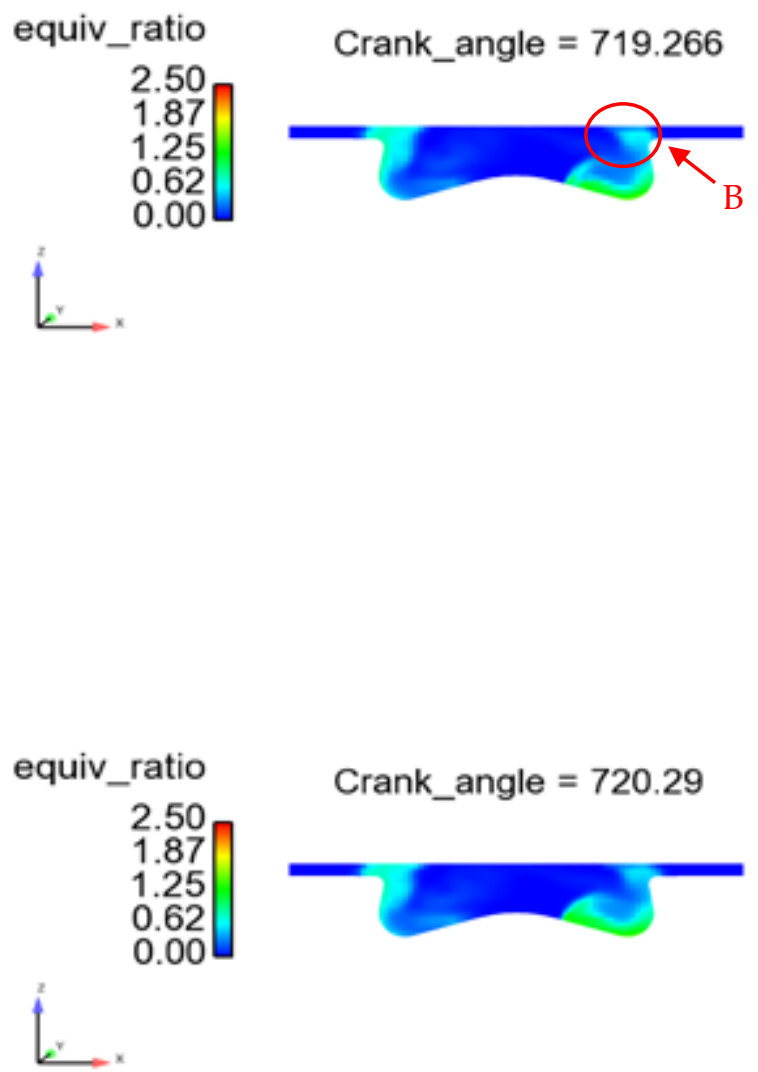

Crank_angle $=720.29$
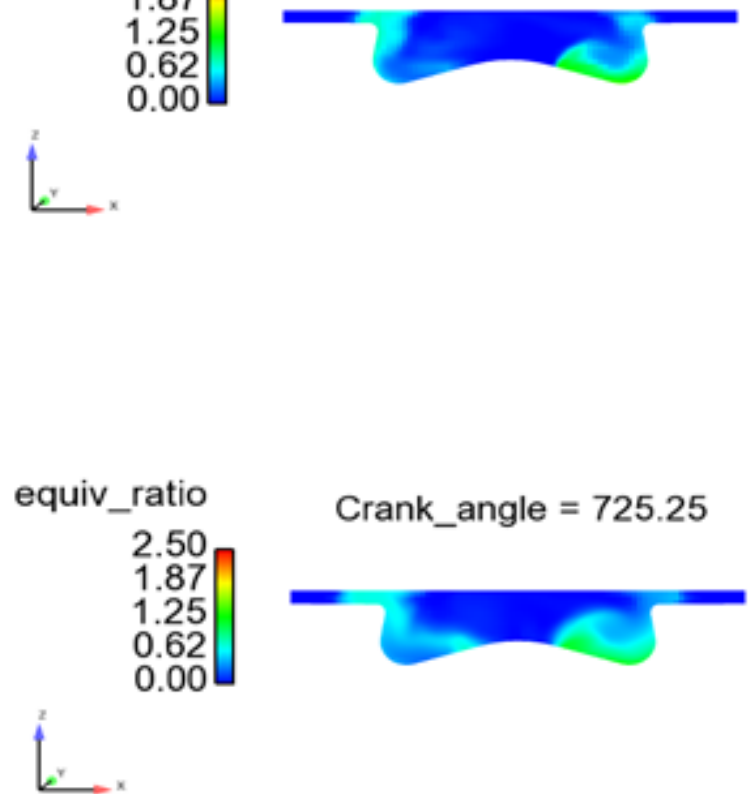

Crank_angle $=725.25$

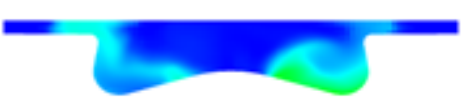

Figure 6. Cross-sections of engine cylinder showing the temperature and equivalence ratio for SOI 25; the customised version of CONVERGE was used.

Simulations were performed from the exhaust valve opening to the end of the expansion stroke of the cycle, using the same setup in both cases. Only the start of injection time and the injected mass were changed; these were taken from the experimental data. Cases run using both versions of CONVERGE could reasonably accurately capture the start of combustion as shown in Figures 8 and 9. At the same time, the peak in-cylinder pressure 
is predicted much more accurately by the software with the new model, compared to its standard version (see Figures 8 and 9). These results are in good agreement with the results of Bertoli and Na Migliaccio [30] based on KIVA-2 simulations for a mono-component diesel spray and the ones presented in [14]. One can see that the difference in peak pressures predicted by the two CONVERGE versions is larger for the early injection stage than for the late injection. This agrees with our findings presented in [12] and highlights how important the new model is in the simulation of combustion processes in PPCI engines.

Liquid fuel mass versus time as predicted by both versions of CONVERGE are shown in Figure 10. The software with the new model predicts more fuel vapour, which leads to lower in-cylinder temperatures due to evaporative cooling. This is linked with the relatively low peak in-cylinder pressures, as predicted by the software with the new model compared with the software with the Amsden et al. model, as shown in Figures 8 and 9.

The difference in predicted vapour mass for both models increases at longer times, as shown in Figure 11. This agrees with the numerical predictions for vaporising sprays at different ambient conditions presented by Kabil et al. [12] using both heating and evaporating models. In the latter analysis, a spray of five-component light naphtha fuel surrogate at engine-like conditions was modelled.

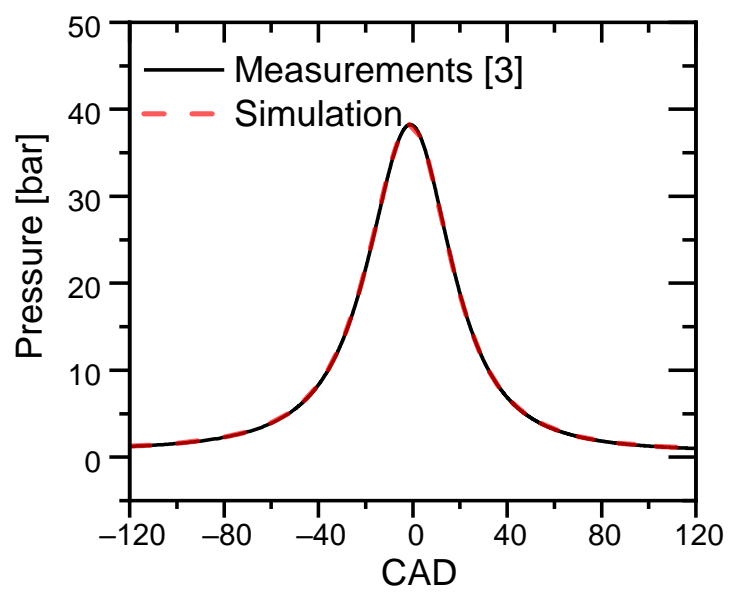

Figure 7. Matching between the experimental motoring curve and that predicted by CONVERGE with the new model implemented into it via UDF (user-defined functions).

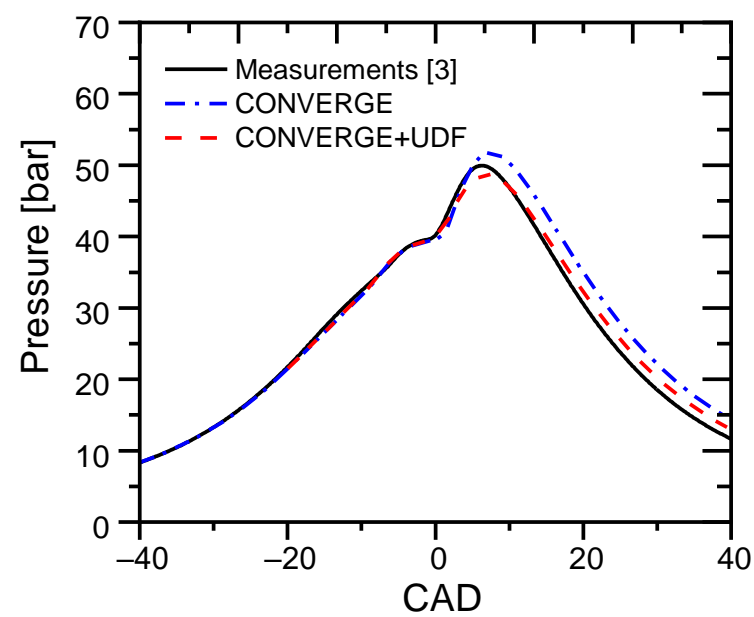

Figure 8. Comparison of in-cylinder pressures inferred from the experimental results, and the results of the simulation using the standard and customised versions of COVERGE at SOI 20 (CAD) crank angle in degrees BTDC (before top-dead-centre). 


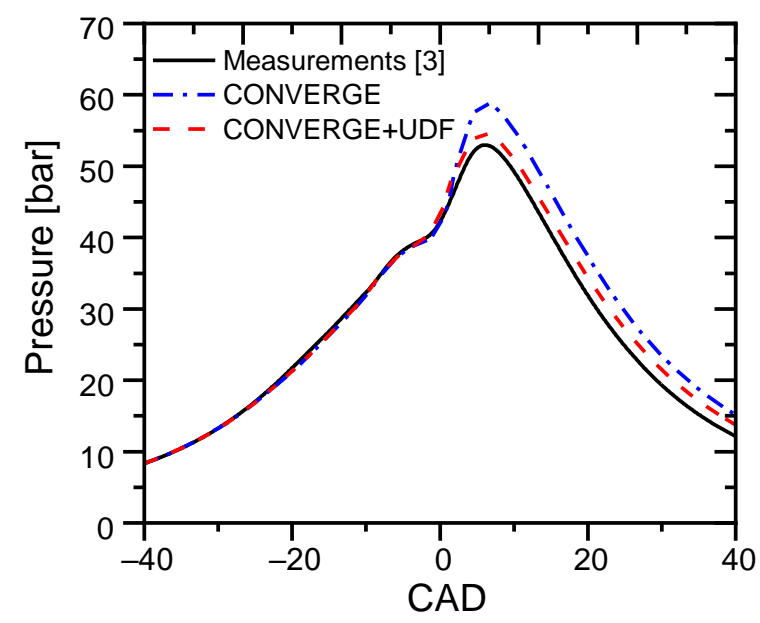

Figure 9. The same as Figure 8 but for SOI 25 CAD BTDC.
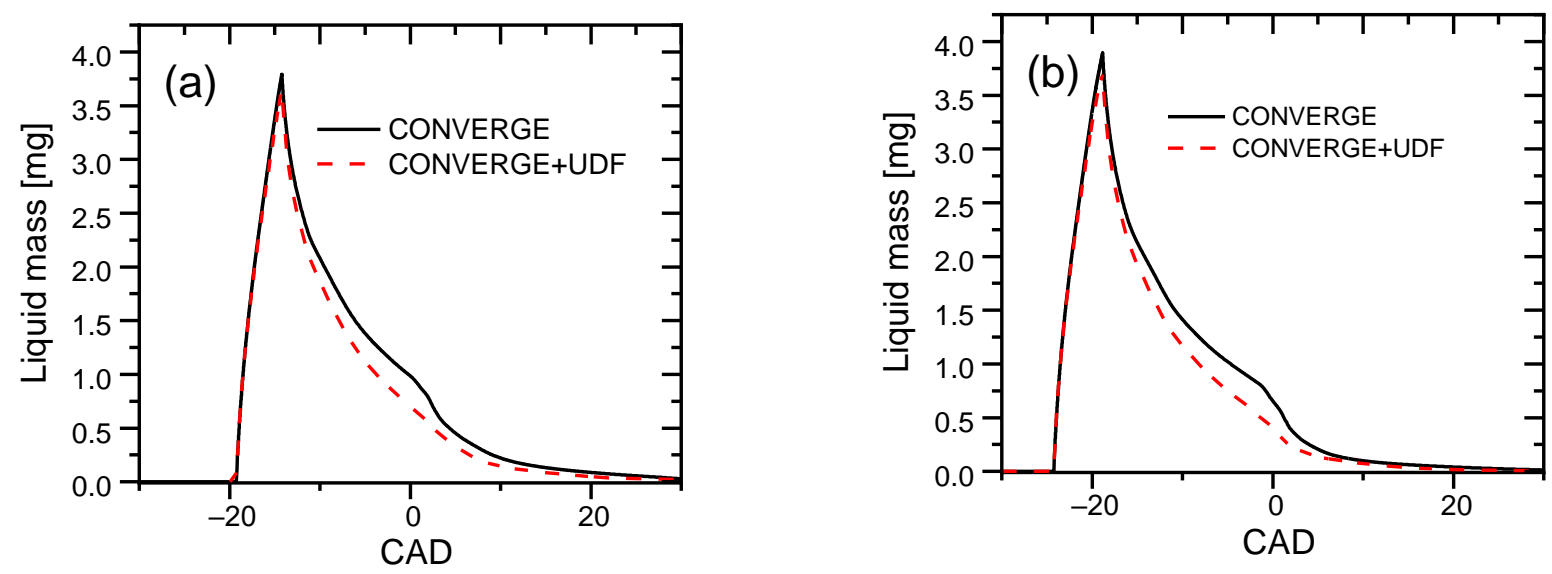

Figure 10. Predicted liquid mass of fuel for: (a) SOI 20; (b) SOI 25 CAD BTDC.
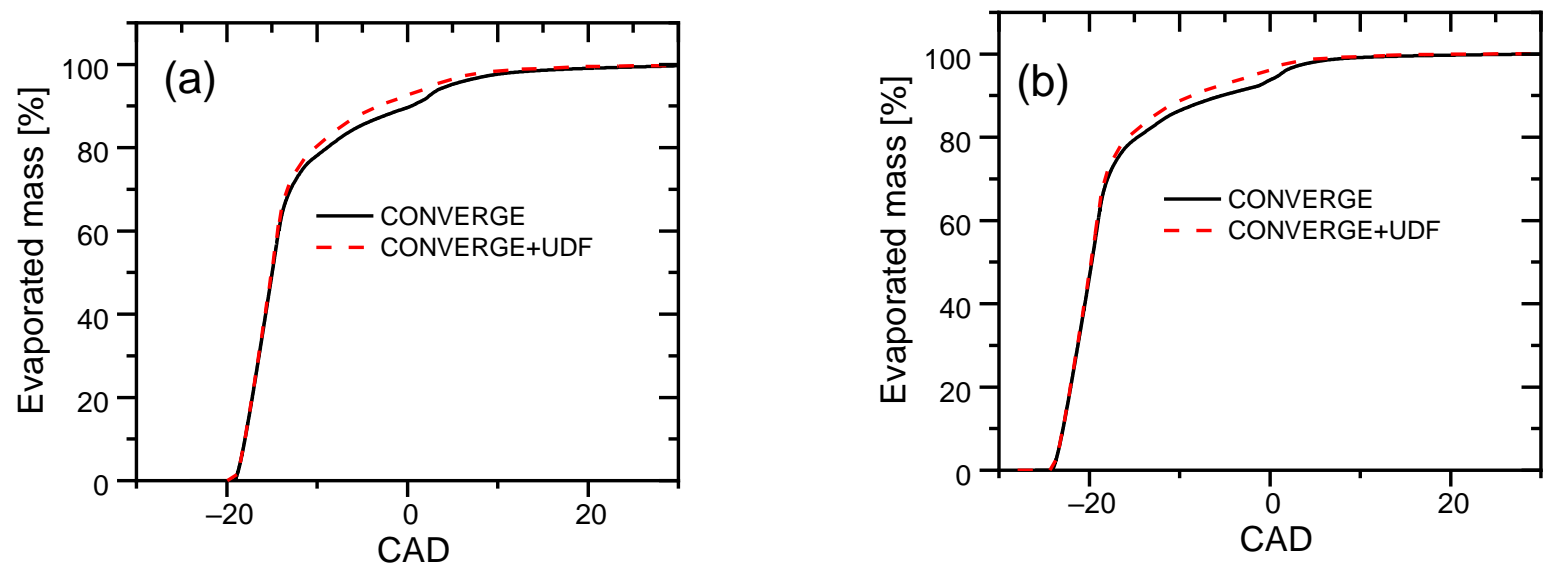

Figure 11. Predicted evaporated fuel mass for: (a) SOI 20; (b) SOI 25 CAD BTDC.

\section{Conclusions}

A new heating and evaporation model based on the analytical solutions to transient heat transfer and species diffusion equations was implemented into the commercial CFD software CONVERGE. The model was validated in the analysis of the heating and evaporation of a single droplet. The results predicted by CONVERGE with the new model 
were found to be closer to the experimental measurements than those based on the built-in version based on the Amsden et al. model.

The customised version (using the ETC/ED models) and original version (using the Amsden et al. model) of CONVERGE were applied to analyse PRF65 hollow-cone spray penetration length. The predictions of both versions of CONVERGE were found to be similar, although some discrepancies between the predictions of the two versions of this software were shown in the vapour mass time history; the customized version of CONVERGE predicted higher rates of evaporation.

The simulation of a PPCI engine at late fuel injection timings was performed. The customised CONVERGE tool allowed us to better capture the peak in-cylinder pressure than the original version of the software. This was ascribed to the fact that the ETC/ED models could predict the size history of fuel droplets more accurately than the original software tool (using the Amsden et al. model). It also predicted higher droplet surface temperatures, which enhanced their breakup. The results of our numerical simulations highlight the importance of properly describing the physical processes in fuel and biofuel sprays, especially in partially premixed combustion engines.

Author Contributions: Conceptualisation, A.E. and I.K.; methodology, I.K.; software, I.K., Y.E.; validation, I.K., J.B., H.G.I.; formal analysis, A.E.; investigation, J.B.; resources, I.K.; data curation, M.A.Q.; writing—original draft preparation, I.K.; writing—review and editing, M.A.Q., A.E., S.S.S.; visualization, M.A.Q.; supervision, A.E., W.A.; project administration, W.A.; funding acquisition, M.A.Q., S.S.S. All authors have read and agreed to the published version of the manuscript.

Funding: This research was funded by the European Commission and the British Council, grant numbers: 2018-1-UK01-KA107-047386 and 2020-1-UK01-KA107-078517 (M.AQ.) and UK EPSRC, grant number: EP/M002608/1 (S.S.S.).

Institutional Review Board Statement: Not applicable.

Informed Consent Statement: Not applicable.

Data Availability Statement: Not applicable.

Acknowledgments: The authors are grateful to Convergent Science for providing a CONVERGE license.

Conflicts of Interest: The authors declare no conflict of interest.

\section{References}

1. Lechner, G.A.; Jacobs, T.J.; Chryssakis, C.A.; Assanis, D.N.; Siewert, R.M. Evaluation of a narrow spray cone angle, advanced injection timing strategy to achieve partially premixed compression ignition combustion in a diesel engine. SAE Trans. 2005, 114, 394-404.

2. Al Qubeissi, M.; El-Kharouf, A. Renewable Energy: Resources, Challenges and Applications; IntechOpen: London, UK, 2020. [CrossRef]

3. Naser, N.; Jaasim, M.; Atef, N.; Chung, S.H.; Im, H.G.; Sarathy, S.M. On the effects of fuel properties and injection timing in partially premixed compression ignition of low octane fuels. Fuel 2017, 207, 373-388. [CrossRef]

4. Amsden, A.A.; O'rourke, P.; Butler, T. KIVA-II: A Computer Program for Chemically Reactive Flows with Sprays; Los Alamos National Lab.: Los Alamos, NM, USA, 1989.

5. Sazhin, S.S.; Elwardany, A.; Sazhina, E.; Heikal, M. A quasi-discrete model for heating and evaporation of complex multicomponent hydrocarbon fuel droplets. Int. J. Heat Mass Transf. 2011, 54, 4325-4332. [CrossRef]

6. Al Qubeissi, M.; Sazhin, S.S.; Elwardany, A.E. Modelling of blended Diesel and biodiesel fuel droplet heating and evaporation. Fuel 2017, 187, 349-355. [CrossRef]

7. Sazhin, S.S. Modelling of fuel droplet heating and evaporation: Recent results and unsolved problems. Fuel 2017, 196, 69-101. [CrossRef]

8. Sazhin, S.; Al Qubeissi, M.; Kolodnytska, R.; Elwardany, A.; Nasiri, R.; Heikal, M. Modelling of biodiesel fuel droplet heating and evaporation. Fuel 2014, 115, 559-572. [CrossRef]

9. Sazhin, S.; Al Qubeissi, M.; Nasiri, R.; Gun'Ko, V.; Elwardany, A.; Lemoine, F.; Grisch, F.; Heikal, M. A multi-dimensional quasi-discrete model for the analysis of Diesel fuel droplet heating and evaporation. Fuel 2014, 129, 238-266. [CrossRef]

10. Sazhin, S.S.; Elwardany, A.; Krutitskii, P.A.; Castanet, G.; Lemoine, F.; Sazhina, E.M.; Heikal, M.R. A simplified model for bi-component droplet heating and evaporation. Int. J. Heat Mass Transf. 2010, 53, 4495-4505. [CrossRef]

11. Elwardany, A.; Sazhin, S.S.; Im, H.G. A new formulation of physical surrogates of FACE A gasoline fuel based on heating and evaporation characteristics. Fuel 2016, 176, 56-62. [CrossRef] 
12. Kabil, I.; Sim, J.; Badra, J.; Eldrainy, Y.; Abdelghaffar, W.; Mubarak Ali, M.J.; Ahmed, A.; Sarathy, S.; Im, H.; Elwardany, A. A surrogate fuel formulation to characterize heating and evaporation of light naphtha droplets. Combust. Sci. Technol. 2018, 190, 1218-1231. [CrossRef]

13. Al-Esawi, N.; Al Qubeissi, M. A new approach to formulation of complex fuel surrogates. Fuel 2021, 283, 118923. [CrossRef]

14. Abdelghaffar, W.A.; Elwardany, A.; Sazhin, S. Modeling of the processes in diesel engine-Litrelike conditions: Effects of fuel heating and evaporation. At. Sprays 2010, 20,737-747. [CrossRef]

15. Rybdylova, O.; Al Qubeissi, M.; Braun, M.; Crua, C.; Manin, J.; Pickett, L.M.; De Sercey, G.; Sazhina, E.; Sazhin, S.; Heikal, M. A model for droplet heating and its implementation into ANSYS Fluent. Int. Commun. Heat Mass Transf. 2016, 76, 265-270. [CrossRef]

16. Rybdylova, O.; Poulton, L.; Al Qubeissi, M.; Elwardany, A.; Crua, C.; Khan, T.; Sazhin, S. A model for multi-component droplet heating and evaporation and its implementation into ANSYS Fluent. Int. Commun. Heat Mass Transf. 2018, 90, 29-33. [CrossRef]

17. Sazhin, S.; Al Qubeissi, M.; Xie, J.-F. Two approaches to modelling the heating of evaporating droplets. Int. Commun. Heat Mass Transf. 2014, 57, 353-356. [CrossRef]

18. Sazhin, S. Droplets and Sprays; Springer: Heidelberg, Germany, 2014; Volume 220.

19. Abramzon, B.; Sirignano, W. Droplet vaporization model for spray combustion calculations. Int. J. Heat Mass Transf. 1989, 32, 1605-1618. [CrossRef]

20. Poling, B.E.; Prausnitz, J.M.; John Paul, O.C.; Reid, R.C. The Properties of Gases and Liquids; McGraw-Hill: New York, NY, USA, 2001; Volume 5.

21. Daiif, A.; Bouaziz, M.; Chesneau, X.; Ali Chérif, A. Comparison of multicomponent fuel droplet vaporization experiments in forced convection with the Sirignano model. Exp. Therm. Fluid Sci. 1998, 18, 282-290. [CrossRef]

22. Wang, L.; Badra, J.A.; Roberts, W.L.; Fang, T. Characteristics of spray from a GDI fuel injector for naphtha and surrogate fuels. Fuel 2017, 190, 113-128. [CrossRef]

23. Richards, K.J.; Senecal, P.K.; Pomraning, E. CONVERGE v2.3 Manual; Convergent Science Inc.: Madison, WI, USA, 2016.

24. Post, S.L.; Abraham, J. Modeling the outcome of drop-drop collisions in Diesel sprays. Int. J. Multiph. Flow 2002, 28, 997-1019. [CrossRef]

25. Sim, J.; Badra, J.; Elwardany, A.; Im, H. Spray Modeling for Outwardly-Opening Hollow-Cone Injector. In Proceedings of the SAE 2016 World Congress \& Exhibition, Detroit, MI, USA, 12-14 April 2016.

26. Badra, J.A.; Sim, J.; Elwardany, A.; Jaasim, M.; Viollet, Y.; Chang, J.; Amer, A.A.; Im, H.G. Numerical Simulations of Hollow Cone Injection and Gasoline Compression Ignition Combustion With Naphtha Fuels. In Proceedings of the 2015 ASME Internal Combustion Engine Division Fall Technical Conference, Houston, TX, USA, 8-11 November 2015; p. V002T006A019.

27. An, Y.; Jaasim, M.; Vallinayagam, R.; Vedharaj, S.; Im, H.G.; Johansson, B. Numerical simulation of combustion and soot under partially premixed combustion of low-octane gasoline. Fuel 2018, 211, 420-431. [CrossRef]

28. Babajimopoulos, A.; Assanis, D.; Flowers, D.; Aceves, S.; Hessel, R. A fully coupled computational fluid dynamics and multi-zone model with detailed chemical kinetics for the simulation of premixed charge compression ignition engines. Int. J. Engine Res. 2005, 6, 497-512. [CrossRef]

29. Liu, Y.-D.; Jia, M.; Xie, M.-Z.; Pang, B. Development of a New Skeletal Chemical Kinetic Model of Toluene Reference Fuel with Application to Gasoline Surrogate Fuels for Computational Fluid Dynamics Engine Simulation. Energy Fuels 2013, 27, 4899-4909. [CrossRef]

30. Bertoli, C.; Na Migliaccio, M. A finite conductivity model for diesel spray evaporation computations. Int. J. Heat Fluid Flow 1999, 20, 552-561. [CrossRef] 